\title{
Determining alkali leaching during accelerated ASR performance testing and in field exposed cubes using cold water extraction (CWE) and $\mu \mathrm{XRF}$
}

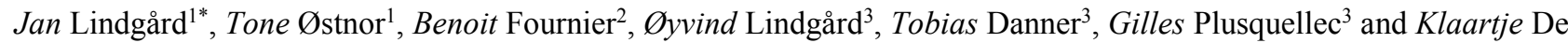 \\ Weerdt ${ }^{3}$ \\ ${ }^{1}$ SINTEF Building and Infrastructure, Trondheim, Norway \\ ${ }^{2}$ LAVAL University, Québec, Canada \\ ${ }^{3}$ NTNU, Structural Engineering, Trondheim, Norway
}

\begin{abstract}
Considerable leaching of alkali metals was documented, both in concrete samples exposed to accelerated laboratory testing and field samples. CWE allowed to quantitatively determine the free alkali metal profiles as a function of the depth. However, CWE cannot account for the changes in the paste content towards a cast surface leading to a seemingly increase in alkali metals. The $\mu \mathrm{XRF}$ allowed to distinguish paste and aggregates. It allowed thereby to determine qualitative $\mathrm{Na}$ and $\mathrm{K}$ profiles in the cement paste phase of the concrete samples. The laboratory exposed samples showed a clear leaching profile into a depth of about $15 \mathrm{~mm}$ after 21 weeks of exposure at $60{ }^{\circ} \mathrm{C}$. Corresponding numbers for the 12 years field exposed cube were $50-60 \mathrm{~mm}$. Alkali sorption by alkali silica gel was detected using the $\mu \mathrm{XRF}$. For the laboratory exposed samples, the prisms prepared with Portland fly ash cement leached less alkali compared to the prisms prepared with ordinary Portland cement, as expected. The leaching in the middle of the prisms estimated based on the $\mu$ XRF profiles agreed rather well with the level of alkali leaching determined based on the analysis of the leachate (i.e. the water below the samples during exposure).
\end{abstract}

\section{Introduction}

Various concrete prism tests have been used world-wide for several decades for alkali-silica reactivity (ASR) performance testing. The aim has been to document the efficiency of various measures, such as adding silica fume, fly ash or slag, to prevent ASR when alkali reactive aggregates are used. However, the reliability of various test procedures has been questioned. The main source of error is alkali leaching from the concrete prisms [1]. Around the world, work is thus still going on to improve the reliability of concrete performance tests and to calibrate the methods to field behaviour, for example in the RILEM TC 258-AAA (2014-2019). The work in this $\mathrm{TC}$ is performed in close co-operation with the Norwegian R\&D project "KPN-ASR" (2014-2018).

As reported by [2], a remarkably high proportion of the in-mixed alkalis were leached out of the concrete prisms during ASR performance testing, leading to reduced prism expansions compared with assumed field behaviour. This conclusion was based on the amount of leached alkalis determined by analysing the leachate in the bottom of the storage containers. However, it is also of interest to document the remaining alkali content in laboratory prisms and in field concrete, including detecting the depth that is influenced by alkali leaching. A pilot study has thus recently been performed.

\subsection{Origin of samples}

There is need for well documented samples to both investigate the extent of alkali leaching and to evaluate the applicability of the methods applied for measuring the remaining internal alkali content.

\subsubsection{Field samples}

As part of the EU PARTNER Project (2002-2006) [3], several monitored $300 \mathrm{~mm}$ concrete cubes were exposed outdoors at eight locations across Europe. During exposure, one cube was stored with its base in a tray filled with water (wet storage), and the other was exposed only to ambient rainfall (dry storage). In 2017, a postdocumentation program was initiated within RILEM TC 258-AAA (2014-2019) focusing on assessment of the environmental impact on ASR. After about 12 years of field exposure, four cores were drilled from each of the 20 dry stored cubes selected for detailed laboratory analyses. From one of these cubes stored in Brevik in Southern Norway (denoted "F2 $(\mathrm{C}+\mathrm{F})-\mathrm{Br}$ " and labelled PARTNER in Table 1 and Table 2), two extra cores were drilled from the side of the cube (Fig. 1). As expected, the measured 
expansion was neglectable for this non-reactive mixture (Table 2) at the time of coring.

\subsubsection{Laboratory samples}

In the Norwegian $38^{\circ} \mathrm{C}$ ASR concrete performance test (NCPT) [4], 100x 100x450 mm concrete prisms (labelled 9027-7) are stored for 1-2 years on grids above water inside sealed containers ( $\sim 100 \%$ relative humidity, $R H)$. After 113 weeks of exposure of a concrete mixture with reactive aggregates and a CEM II/A-V cement (Table 2), producing a prism expansion of about $0.040 \%$, samples were collected (Fig. 2) for internal alkali metals measurements (see 2.3).

Corresponding samples were collected (Fig. 3) from two $70 \times 70 \times 280 \mathrm{~mm}$ concrete prisms (labelled C1-60-1 and C5-60-1) exposed on grids above water inside sealed containers (100\% RH) according to the RILEM AAR-4.1 $60^{\circ} \mathrm{C}$ ASR aggregate test method [5]. After 21 weeks of storage of these prisms made with a non-reactive aggregate (Table 2), the measured prism expansion was about $0.010 \%$.

\subsection{Research question}

The aim of this study is to document the remaining internal alkali content and alkali leaching profiles both in concrete samples exposed to accelerated laboratory testing and field exposed concrete samples. At the same time, the suitability of the methods applied is discussed.

\section{Materials and methods}

\subsection{Concrete samples}

Table 2 gives an overview over the concrete samples investigated in this study, the labelling used, the projects they originate from, the aggregates used, the binder type, the $\mathrm{w} / \mathrm{b}$ ratio, the alkali content in the binder, and finally the total alkali content of the concretes.

\subsection{Sampling and preparation}

During drilling of the concrete cores and cutting of the samples from the prisms with a diamond blade saw, a minimum of cooling water was used. The surfaces were wiped out with a moist cloth immediately after cutting and sawing, and then wrapped tight in plastic foil to avoid drying.

For CWE, the concrete was profile ground to powder in sections at different depths. Table 1 gives an overview over the sections ground in the investigated samples.

\subsection{Methods}

\subsubsection{CWE}

The cold water extraction (CWE) method was used to determine the free alkali metal content per mass of concrete. The results were not corrected for potential alkali release from the aggregates during the CWE procedure as suggested by [6].

For CWE, $20 \mathrm{~g}$ profile ground concrete powder was mixed with $20 \mathrm{~g}$ of deionized water and stirred for $5 \mathrm{~min}$. The suspension was filtrated for approx. 1 min using a water pump and a Grade $40,8 \mu \mathrm{m}$ particle retention Whatman cellulose filter. Finally, each solution was diluted 10 times with deionized water and acidified with $\mathrm{HNO}_{3}$ to obtain a final $\left[\mathrm{HNO}_{3}\right]$ concentration of $0.1 \mathrm{~mol} / \mathrm{l}$. The solutions were analysed for $\mathrm{Na}$ and $\mathrm{K}$ by flame atomic absorption spectroscopy (FAAS) of type "SpectrAA-400".

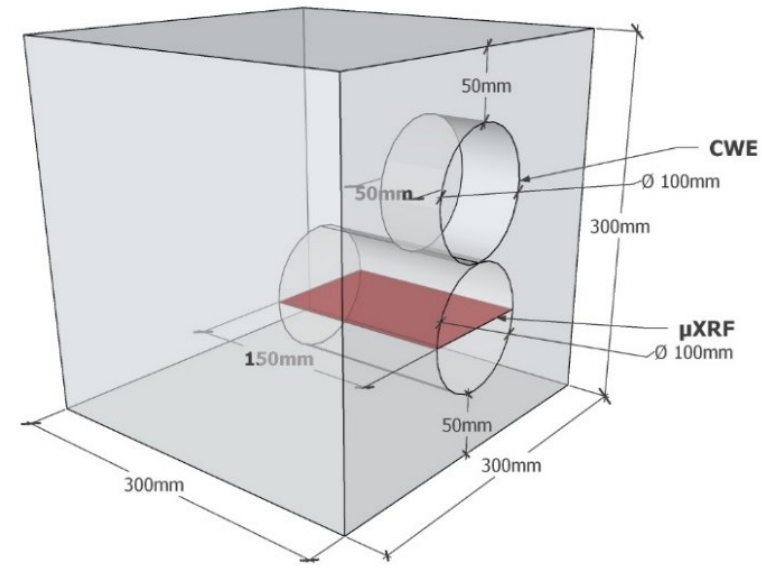

Fig. 1 : Sampling from the PARTNER cube.

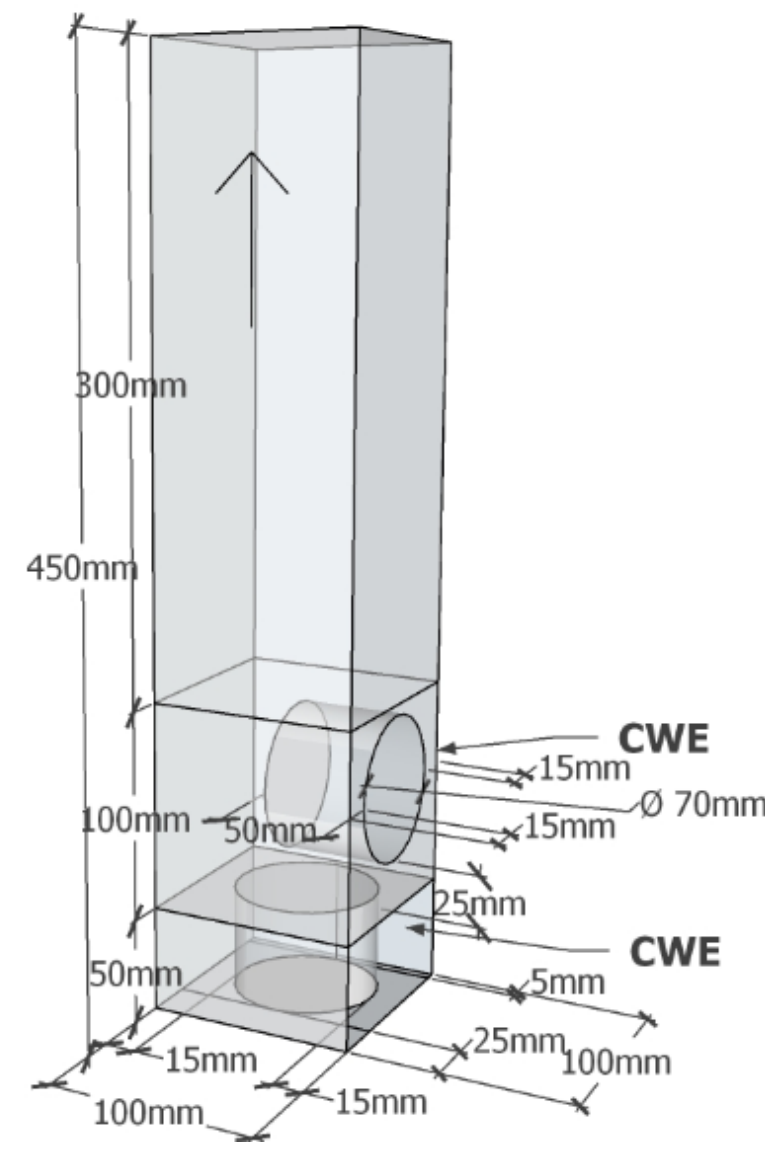

Fig. 2 : Sampling from prism 9027-7. 


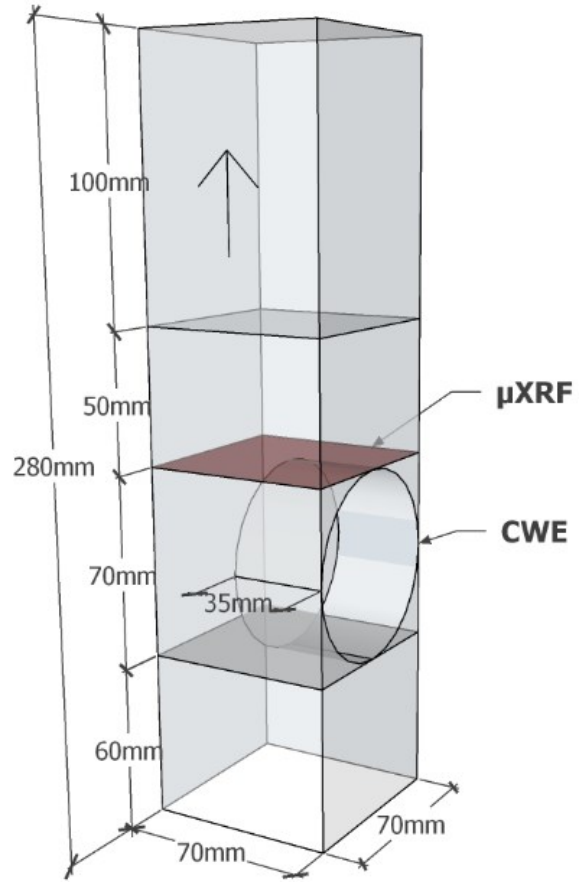

Fig. 3 : Sampling from prism C1-60-1 and C5-60-1.

\section{3. $2 \mu X R F$}

A M4 Tornado $\mu$ XRF from Bruker equipped with an Ag $\mathrm{X}$-ray tube and two SDD detectors was used to determine elemental maps on sawn concrete surfaces. For the elemental mapping, the X-ray tube was set to $50 \mathrm{kV}$ and $600 \mu \mathrm{A}$, the vacuum to $20 \mathrm{mbar}$, and the two SDD detectors were switch on. The X-rays were focused to a $20 \mu \mathrm{m}$ spot size. The following elements were analysed: $\mathrm{Al}, \mathrm{Ca}, \mathrm{Fe}, \mathrm{K}, \mathrm{Mg}, \mathrm{Na}, \mathrm{S}$ and $\mathrm{Si}$.

For the laboratory samples (C1-60-1 and C5-60-1), one overview map was made with a stepsize of $25 \mu \mathrm{m}$ and a collection time of $1 \mathrm{~ms}$ per pixel. For the elemental profiles, 8 sections with a height of about $30 \mathrm{~mm}$ and a width of 3 to $10 \mathrm{~mm}$ were scanned from the exposed surface inwards (illustrated in Fig. 4). The step width was $25 \mu \mathrm{m}$ and collection time $10 \mathrm{~ms}$ per pixel. For the field sample (PARTNER), 15 sections with a height of about $36 \mathrm{~mm}$ and a width of $10 \mathrm{~mm}$ were scanned with a step width of $30 \mu \mathrm{m}$ and collection time of $10 \mathrm{~ms}$ per pixel.

Fig. 5 shows the collected elemental maps for the section $30-40 \mathrm{~mm}$ of the sample C5-60-1. The software was used to differentiate between two "phases" in each section: the aggregates and the paste. The differentiation was based on the S-map as illustrated in Fig. 6. The Na and $\mathrm{K}$ were quantified in the paste of each of the sections to obtain alkali metal profiles. The results are expressed in normalised wt.\%, meaning that the wt.\% of all analysed elements sum up to $100 \%$.

Table 1 : Overview over the profile ground section for the investigated samples

\begin{tabular}{|c|l|}
\hline Labelling & Section depth from the surface $(\mathbf{m m})$ \\
\hline PARTNER & $\begin{array}{l}0-3,3-6,6-9,9-12,12-15,15-20,20-30, \\
30-40,40-50,100-150\end{array}$ \\
\hline $9027-7$ & $\begin{array}{l}0-3,3-6,6-9,9-12,12-15,15-20,20-30, \\
30-40,40-44\end{array}$ \\
\hline C1-60-1 & $0-3,3-7,7-11,11-15,15-20,20-27,27-35$ \\
\hline C5-60-1 & $0-3,3-7,7-11,11-15,15-20,20-27,27-35$ \\
\hline
\end{tabular}

\subsubsection{Leachate}

The procedure used for sampling of liquid from the bottom of the storage containers for the alkali leachate measurements is described in [7] and [8]. The concentration of alkalis, sodium $[\mathrm{Na}]$ and potassium [K] (in $\mathrm{mg} / \mathrm{l}$ ), in all the samples collected was analysed by flame atomic absorption spectroscopy (FAAS) of type "SpectrAA-400".

Table 2 : Overview over the investigated samples and the labelling used. The aggregates used, the $\mathrm{w} / \mathrm{b}$ ratio and the binder composition are given for the different samples. The alkali metal content as $\mathrm{Na}_{2} \mathrm{O}, \mathrm{K}_{2} \mathrm{O}$ and $\mathrm{Na}_{2} \mathrm{O}_{\text {eq }}$ are given with respect to the binder (in \%) and the concrete (in $\mathrm{kg} / \mathrm{m}^{3}$ ).

\begin{tabular}{|c|c|c|c|c|c|c|c|c|c|c|c|c|}
\hline \multirow[b]{2}{*}{ Project } & \multirow[b]{2}{*}{ Object } & \multirow[b]{2}{*}{ Labelling } & \multicolumn{2}{|c|}{ Aggregate } & \multicolumn{4}{|c|}{ Binder } & \multicolumn{4}{|c|}{ Concrete } \\
\hline & & & Fine & Coarse & Type & $\begin{array}{c}\mathrm{Na}_{2} \mathrm{O} \\
\%\end{array}$ & $\begin{array}{c}\mathrm{K}_{2} \mathrm{O} \\
\% \\
\end{array}$ & $\begin{array}{c}\mathrm{Na}_{2} \mathrm{O}_{\text {eq }} \\
\%\end{array}$ & $\begin{array}{l}\text { Binder } \\
\mathrm{kg} / \mathrm{m}^{3}\end{array}$ & $\begin{array}{l}\mathrm{NaOH} \\
\mathrm{kg} / \mathrm{m}^{3}\end{array}$ & $\begin{array}{l}\mathrm{Na}_{2} \mathrm{O}_{\text {eq }} \\
\mathrm{kg} / \mathrm{m}^{3}\end{array}$ & $\mathrm{w} / \mathrm{b}$ \\
\hline PARTNER & $\begin{array}{l}\text { Field exposed cube } \\
300 \times 300 \times 300 \mathrm{~mm}^{3}\end{array}$ & PARTNER & $\begin{array}{c}\text { Limestone } \\
(\mathrm{NR})\end{array}$ & $\begin{array}{c}\text { Limestone } \\
(\mathrm{NR})\end{array}$ & CEM I & 0,46 & 1,20 & 1,25 & 440 & 0 & 5,50 & 0,50 \\
\hline $\begin{array}{c}\text { Commercial } \\
\text { testing }\end{array}$ & $\begin{array}{c}\text { Lab.prism } \\
100 \times 100 \times 450 \mathrm{~mm}^{3}\end{array}$ & $9027-7$ & $\begin{array}{c}\text { Natural } \\
\text { sand (R) }\end{array}$ & $\begin{array}{c}\text { Cataclasite } \\
(\mathrm{R})\end{array}$ & $\begin{array}{l}\text { CEM II/A-V } \\
\text { (18\% fly ash) }\end{array}$ & 0,58 & 1,21 & 1,38 & 450 & 1,00 & 7,01 & 0,44 \\
\hline \multirow{4}{*}{ KPN-ASR } & \multirow{4}{*}{ 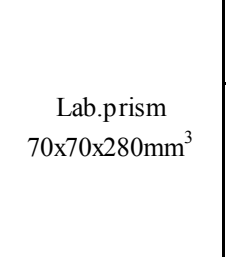 } & C1-60-1 & $\begin{array}{l}\text { Limestone } \\
\text { (NR) }\end{array}$ & $\begin{array}{c}\text { Limestone } \\
\text { (NR) }\end{array}$ & CEM I & 0,50 & 1,09 & 1,22 & 445 & 0 & 5,37 & 0,50 \\
\hline & & \multirow{3}{*}{ C5-60-1 } & \multirow{3}{*}{$\begin{array}{l}\text { Limestone } \\
\text { (NR) }\end{array}$} & \multirow{3}{*}{$\begin{array}{l}\text { Limestone } \\
\text { (NR) }\end{array}$} & CEM I & 0,50 & 1,09 & 1,22 & 355 & 0 & & \\
\hline & & & & & Fly ash & 1,08 & 2,01 & 2,41 & 90 & 0 & & \\
\hline & & & & & $\begin{array}{c}\text { CEM I }(80 \%)+ \\
\text { fly ash }(20 \%)\end{array}$ & & & & 445 & 0 & 6,42 & 0,50 \\
\hline
\end{tabular}




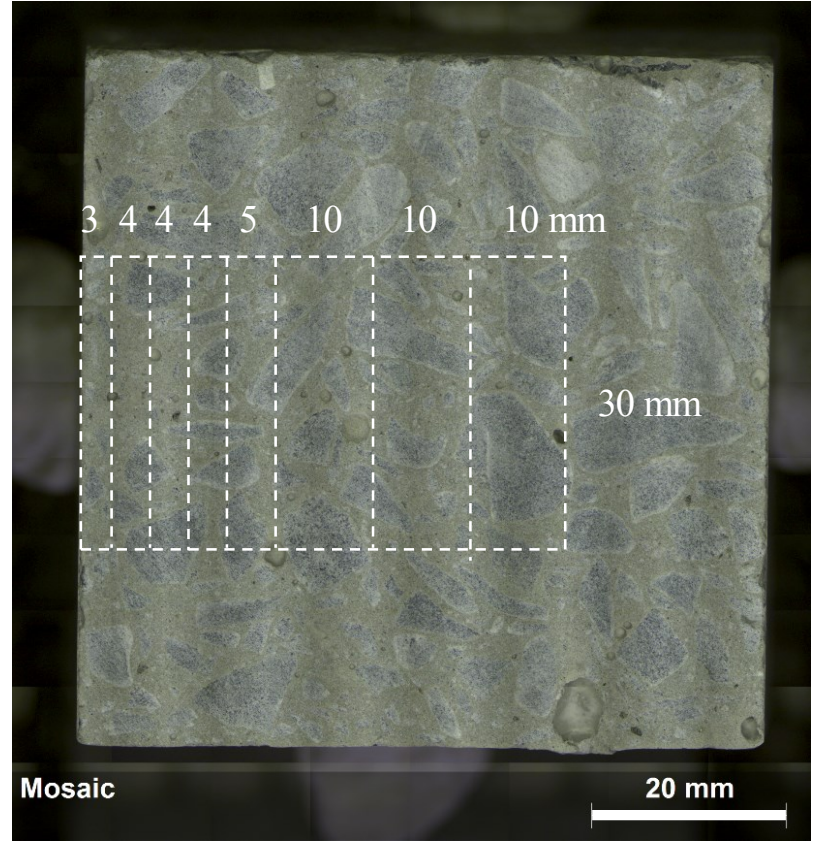

Fig. 4 : Mosaic image of the C5-60-1 sample taken with the $\mu \mathrm{XRF}$. The white dotted lines indicate the sections mapped with the $\mu \mathrm{XRF}$ to obtain the alkali metal profiles. The numbers indicate the width and height of the sections taken.

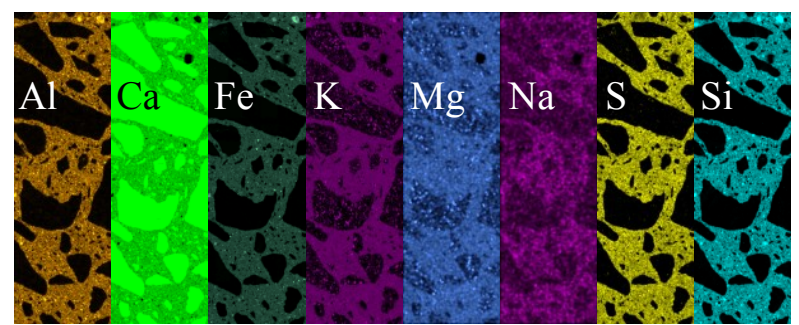

Fig. 5 : Elemental maps determined with the $\mu \mathrm{XRF}$ of section 30-40 mm of sample C5-60-1.

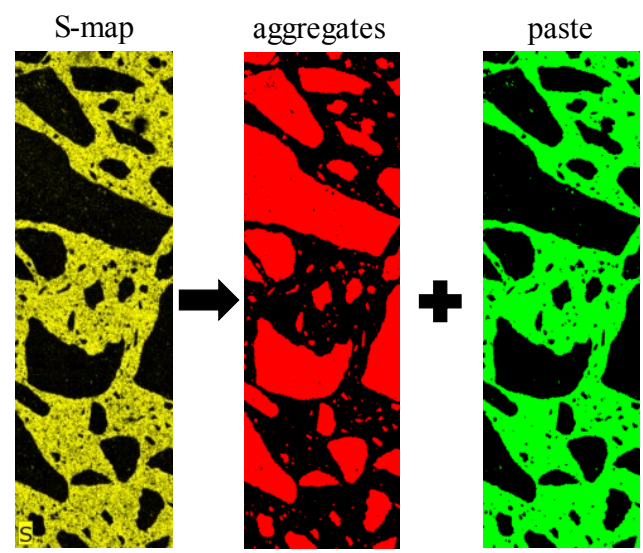

Fig. 6 : Demonstration of the differentiation between aggregates (red) and paste (green) in section $30-40 \mathrm{~mm}$ of sample C5-60-1 using the $\mathrm{S}$ elemental map.

\section{Results and discussion}

\subsection{CWE}

Fig. 7 shows the $\mathrm{Na}_{2} \mathrm{O}_{\text {eq }}$-profiles in $\mathrm{kg} / \mathrm{m}^{3}$ of concrete for the examined samples as a function of the depth from the leached surface determined by CWE. Fig. 8 and Fig. 9 show the corresponding $\mathrm{K}_{2} \mathrm{O}$ and $\mathrm{Na}_{2} \mathrm{O}$-profiles.

One can observe an increasing trend in the alkali metals in the outermost section for all investigated samples. In the case of the PARTNER cube, the increase is not only in the outermost section, but it extends to the outer $15 \mathrm{~mm}$. An increase in the alkali content towards the surface can be attributed to Wick action and/or to an increase in the paste volume in the concrete in these sections.

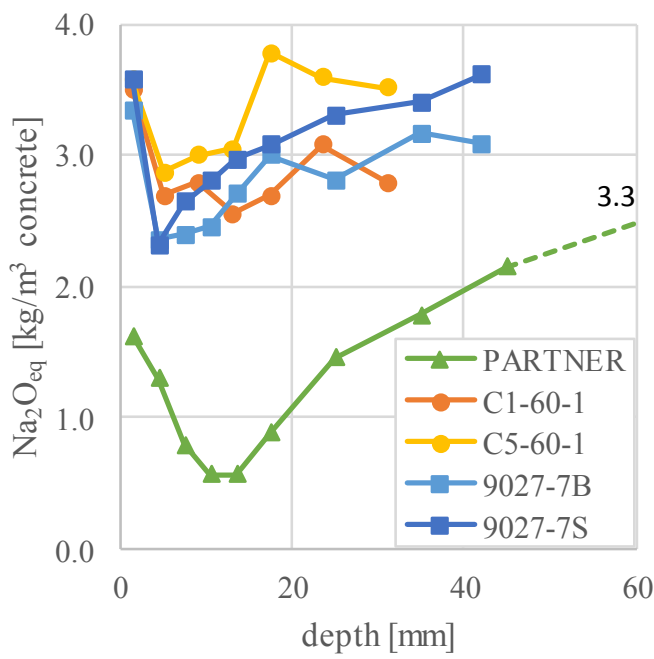

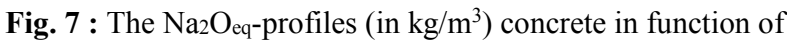
the depth of the exposed surface (in $\mathrm{mm}$ ) obtained by CWE for the examined samples. The $3.3 \mathrm{~kg} / \mathrm{m}^{3} \mathrm{Na}_{2} \mathrm{O}_{\text {eq }}$ indicated in the graph reflects the content determined in a section taken at a depth of approx. $100 \mathrm{~mm}-150$.

Deeper into the samples we observe a decrease in the alkali metal content from the centre of the sample towards the surface. This indicates leaching. The PARTNER sample shows a much higher extent of alkali leaching compared to the laboratory exposed samples. This could be expected, as the PARTNER cube has been exposed outdoors for over 12 years allowing extensive leaching, whereas the other samples had only a limited time of exposure in the laboratory. At casting, all the concretes had a nominal alkali content $>5.3 \mathrm{~kg} / \mathrm{m}^{3} \mathrm{Na}_{2} \mathrm{O}_{\text {eq }}$ (Table 2).

The $\mathrm{K}_{2} \mathrm{O}$ levels are higher than the $\mathrm{Na}_{2} \mathrm{O}$ levels for all samples except for the 9027-7, when comparing Fig. 8 and Fig. 9. This is as expected, as the $\mathrm{K}_{2} \mathrm{O}$ levels are about double as high as the $\mathrm{Na}_{2} \mathrm{O}$ levels in the cement and the 9027-7 sample was boosted with $1.0 \mathrm{~kg} \mathrm{NaOH}$ per $\mathrm{m}^{3}$ of concrete (Table 2). 


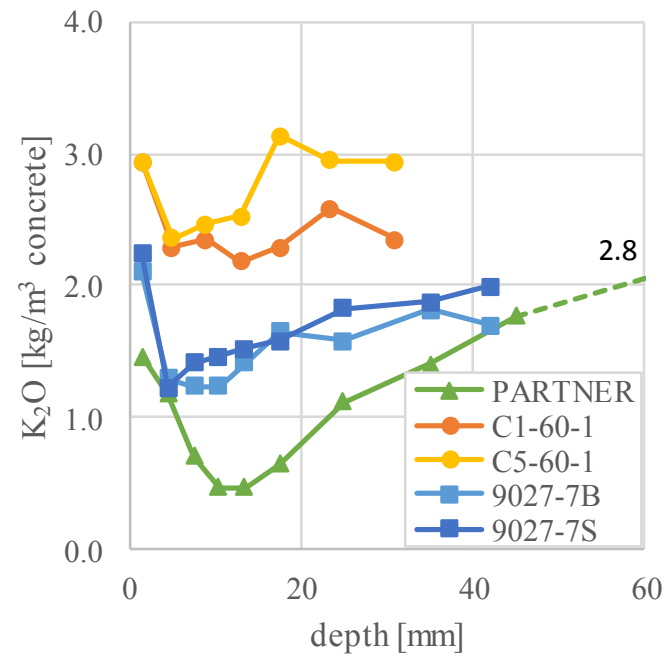

Fig. 8 : The $\mathrm{K}_{2} \mathrm{O}$-profiles (in $\mathrm{kg} / \mathrm{m}^{3}$ ) concrete in function of the depth of the exposed surface (in $\mathrm{mm}$ ) obtained by CWE for the examined samples. The $2.8 \mathrm{~kg} / \mathrm{m}^{3} \mathrm{~K}_{2} \mathrm{O}$ indicated in the graph reflects the content determined on a section taken at a depth of approx. $100 \mathrm{~mm}-150$.

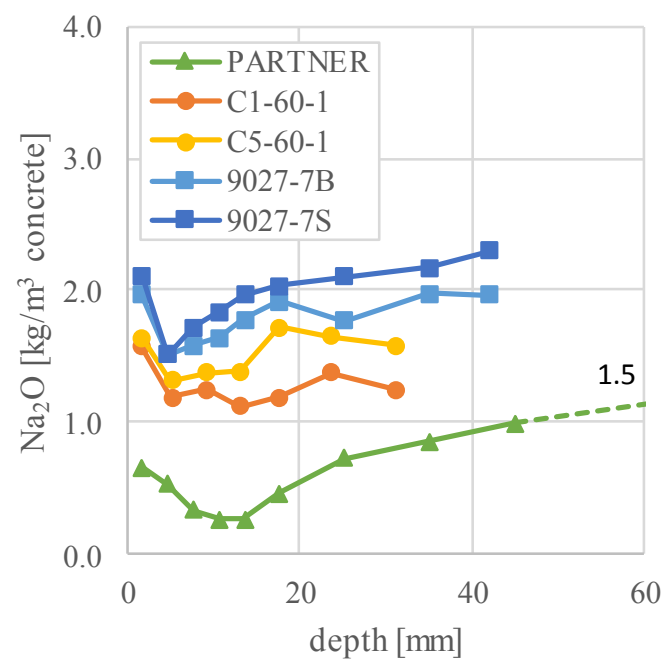

Fig. 9 : The $\mathrm{Na}_{2} \mathrm{O}$-profiles (in $\mathrm{kg} / \mathrm{m}^{3}$ concrete) in function of the depth of the exposed surface (in $\mathrm{mm}$ ) obtained by CWE for the examined samples. The $1.5 \mathrm{~kg} / \mathrm{m}^{3} \mathrm{Na}_{2} \mathrm{O}$ indicated in the graph reflects the content determined on a section taken at a depth of approx. $100 \mathrm{~mm}-150$.

\section{$3.2 \mu X R F$}

Fig. 10 shows the K-map of the sawn surface of the C560-1 sample. The color code gives a relative measure for the amount of $\mathrm{K}$ present in the analysed pixel. The aggregates (limestone) have a relatively low $\mathrm{K}$ content as they are dark blue, whereas the paste contains relatively more $\mathrm{K}$ as the color goes from green to yellow and even red. The color of the paste goes from red and yellow in the centre to more greenish towards the exposed edges of the prism, suggesting leaching of $\mathrm{K}$.

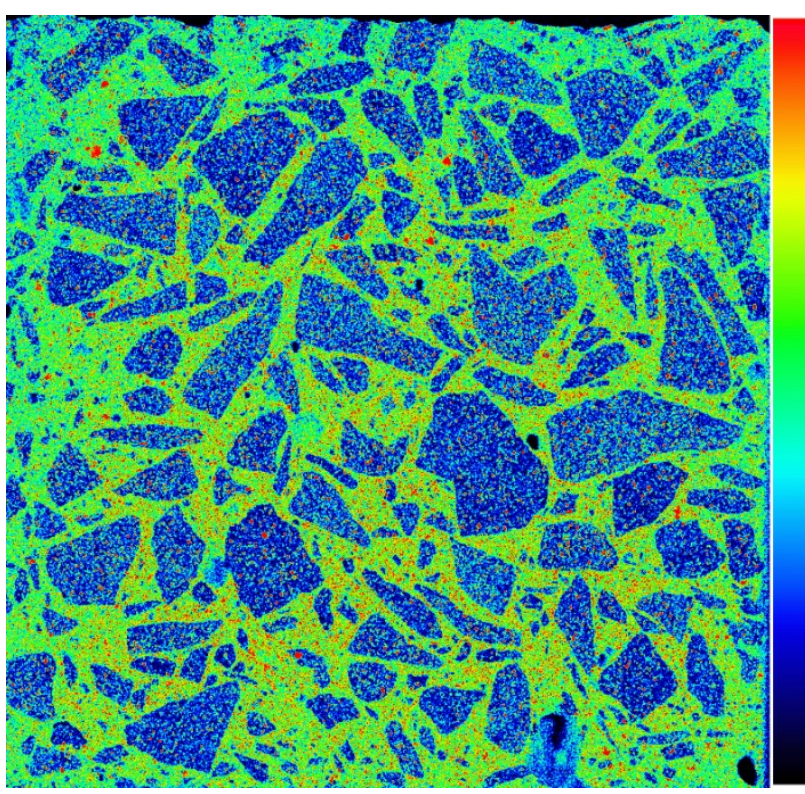

Fig. 10 : K-map of a sawn concrete surface of the C5-60-1 sample. The closer the color is to red the higher is the relative content of $\mathrm{K}$. The dimensions of the sample are $70 \times 70 \mathrm{~mm}$.

Fig. 11, Fig. 12 and Fig. 13 show the $\mathrm{Na}$ and $\mathrm{K}$ profiles in the cement paste of the samples C1-60-1, C5-60-1 and PARTNER. Fig. 14 shows the corresponding area \% of paste in the sections. No $\mu \mathrm{XRF}$ profiles were obtained for the 9027-7 sample.

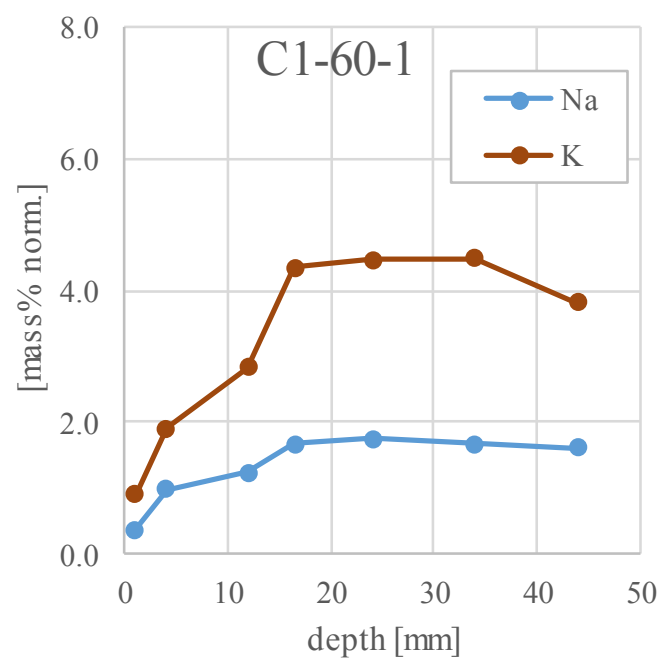

Fig. 11 : The elemental profiles for $\mathrm{Na}$ and $\mathrm{K}$ in the cement paste of the concrete sample C1-60-1 as a function of depth from the leached surface.

The $\mathrm{K}$ level is higher than the $\mathrm{Na}$ in all investigated samples. This is in line with the approx. double as high $\mathrm{K}$ content in the cements compared to $\mathrm{Na}$, as mentioned earlier in relation to the CWE results.

There is a large absolute difference between the alkali metal level in the C1-60-1 and C5-60-1 sample, which we cannot explain currently. There is a need to further investigate how to use the $\mu \mathrm{XRF}$ data quantitatively. Nevertheless, qualitatively the results are consistent and can be repeated. 


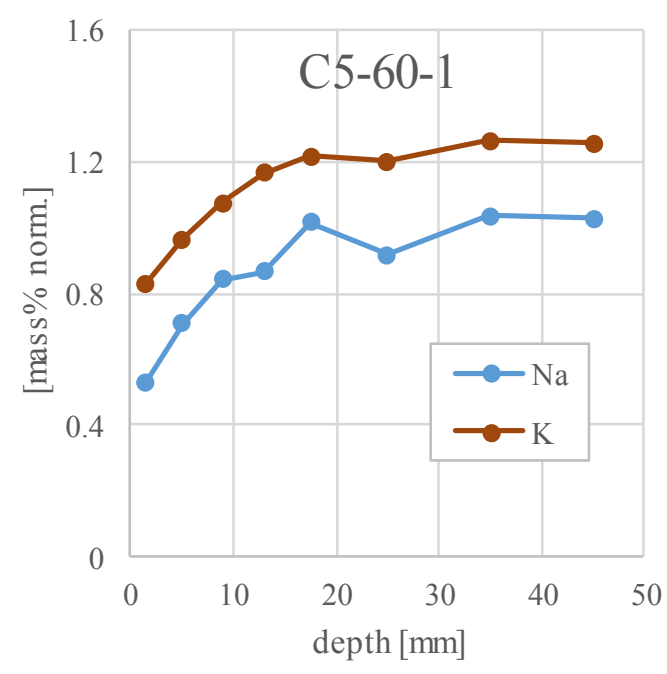

Fig. 12 : The elemental profiles for $\mathrm{Na}$ and $\mathrm{K}$ in the cement paste of the concrete sample C5-60-1 as a function of depth from the leached surface.

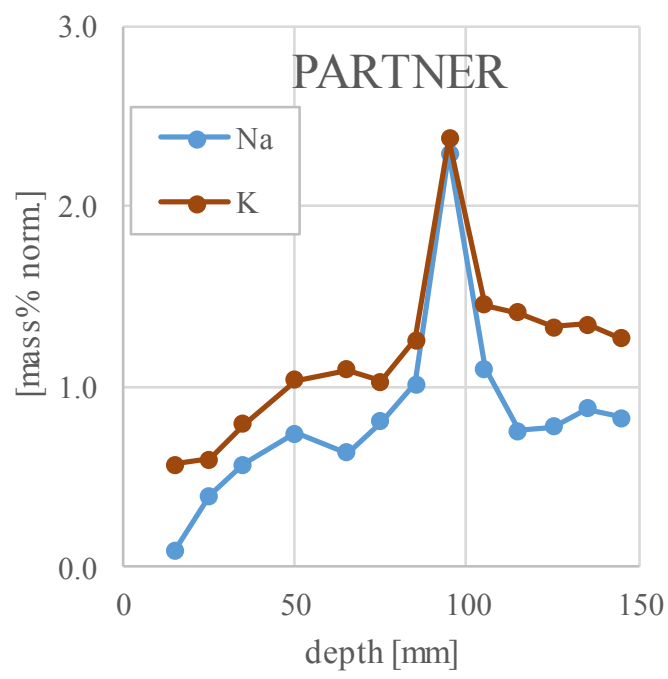

Fig. 13 : The elemental profiles for $\mathrm{Na}$ and $\mathrm{K}$ in the cement paste of the concrete sample PARTNER as a function of depth from the leached surface.

The laboratory exposed samples (C1-60-1 and C5-601) showed a clear leaching profile in the outer $15 \mathrm{~mm}$. Deeper in, the alkali metal levels reach a plateau. In the outermost section, no increase in the alkali metal content was observed with the $\mu \mathrm{XRF}$. This indicates that the increase in alkali metals at the outermost section observed by CWE was caused by an increase in the cement paste content. The increase in cement paste content was also confirmed in Fig. 14. It should be noted that the paste fraction determined as area $\%$ by $\mu \mathrm{XRF}$ has a large scatter as it only represents one 2D section. In a previous study, we used thermogravimetric analysis to determine the paste content in profile ground concrete [6]. This was however not done here.

As the alkali levels in the laboratory exposed samples (C1-60-1 and C5-60-1) plateau in the middle of the prism, one could assume that the inner sections are not leached, and thereby represent the initial alkali level of the concrete. This allows us to estimate the percentage of alkali leached out based on the $\mu$ XRF-profiles. We assumed symmetry of the leaching profile on both sides of the sample. For half the prism (i.e. depth 0-35 mm), we subtracted the actual alkali level in each sub-section (representing a given depth from the surface) from the maximum level (the plateau level) and multiplied it by the width of the sub-section. The sum of these values was divided by the plateau level multiplied with the total width of all sections $(=35 \mathrm{~mm})$. This was done for both $\mathrm{K}$ and $\mathrm{Na}$, and the result is the percentage of $\mathrm{K}$ and $\mathrm{Na}$ leached. For C1-60-1, about $21 \%$ of the $\mathrm{K}$ and $20 \%$ of $\mathrm{Na}$ had leached. The corresponding numbers for $\mathrm{C} 5-60-1$ were $7 \% \mathrm{~K}$ and $11 \% \mathrm{Na}$. This corresponds to $21 \%$ leaching in $\mathrm{Na}_{2} \mathrm{O}_{\text {eq }}$ for $\mathrm{C} 1-60-1$ and $9 \%$ for $\mathrm{C} 5-60-1$. It should be noted that these leaching percentages are not representative for the entire concrete prism. The top of the prism and the bottom part typically leaches more than the middle part of the prism [2].

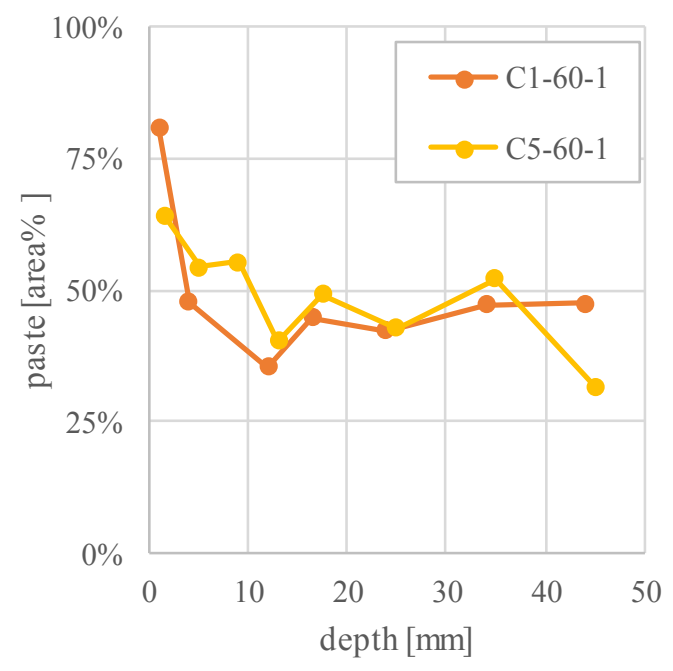

Fig. 14 : The area $\%$ of paste in the sections as a function of the depth from the surfaces determined using the phase differentiation with the $\mu \mathrm{XRF}$.

The field sample, PARTNER, shows more extensive leaching. The alkali level seems to plateau at a depth of $60-70 \mathrm{~mm}$ from the exposed surface. Due to problems with the $\mu \mathrm{XRF}$, the map of the outer $0-10 \mathrm{~mm}$ section was not recorded. At a depth just below $100 \mathrm{~mm}$, a peak in the $\mathrm{Na}$ and $\mathrm{K}$ content is observed. This peak has been attributed to the presence of alkali silica gel, which sorbs considerable amounts of alkali metals. At the same depth, a clear increase in $\mathrm{Si}$ and decrease in $\mathrm{Ca}$ was noted. The presence of alkali silica gel is peculiar in this sample, as the aggregates are inert limestone. However, one reactive aggregate particle must have found its way into this concrete.

\subsection{Leachate}

For the laboratory exposed samples, the total amount of alkalis leached out from the prisms could be determined based on the amount of leachate and the concentration of 
alkalis in the leachate. For C1-60-1, about $33 \%$ of the initial alkali content of the prism (in $\mathrm{kg} / \mathrm{m}^{3} \mathrm{Na}_{2} \mathrm{O}_{\text {eq }}$ of concrete) was found in the leachate. For C5-60-1, about $9 \%$ of the initial alkali had leached. For both, this corresponds quite well with the alkali leaching estimated based on the $\mu \mathrm{XRF}$ profiles in the middle of the prisms (see 3.2) when taking into account the expected higher leaching in the top and bottom of the prisms (the numbers given in 3.2 are from the middle part of the prisms).

Fig. 15 shows the initial alkali content of the concrete as $\mathrm{Na}_{2} \mathrm{O}_{\text {eq }}$ in $\mathrm{kg} / \mathrm{m}^{3}$ of concrete based on the concrete recipe (alkali content of the binder - Table 2 ). In addition, the average remaining alkali content in the concrete after leaching is given. This was calculated by subtracting the leached amount of alkali found in the leachate from the initial alkali content in the concrete based on the recipe. Finally, Fig. 15 also shows the free alkali content in the inner section of the concrete sample determined by CWE.

It should be noted that the remaining average alkali content is an average value for the entire prism. As observed by $\mathrm{CWE}$ and $\mu \mathrm{XRF}$, the outer section of the prisms will leach more than the bulk. Furthermore, the top and bottom part of the prism will typically leach more than the middle part [2].

8

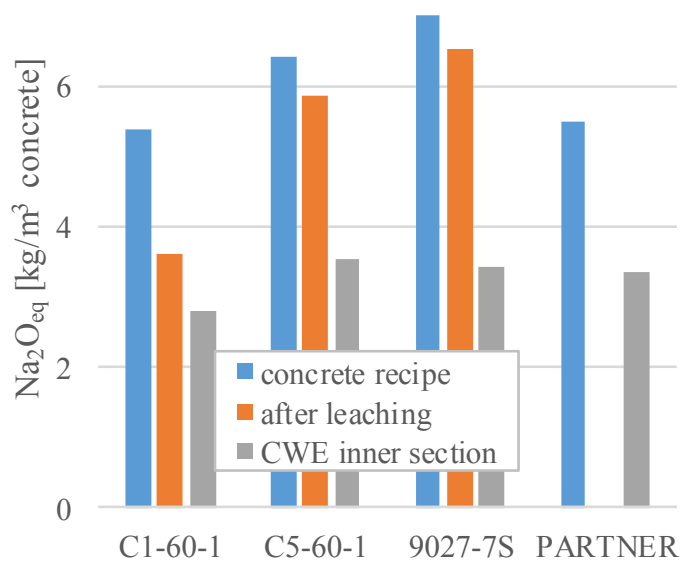

Fig. 15 : The $\mathrm{Na}_{2} \mathrm{O}_{\text {eq }}$ content (in $\mathrm{kg} / \mathrm{m}^{3}$ of concrete) based on the concrete recipe (Table 2), the average alkali content in the sample after leaching, and the alkali content in the inner section of the concrete sample obtained by CWE.

Fig. 16 shows the remaining average $\% \mathrm{Na}_{2} \mathrm{O}_{\text {eq }}$ in the prisms after leaching compared to the alkali content initially in the concrete (Table 2). The difference between them reflects the extent of leaching. The concrete prepared with Portland cement (C1-60-1) showed relatively more pronounced alkali leaching than the concretes containing fly ash cement (C5-60-1 and 90277). This is in accordance with previous experiences [2].

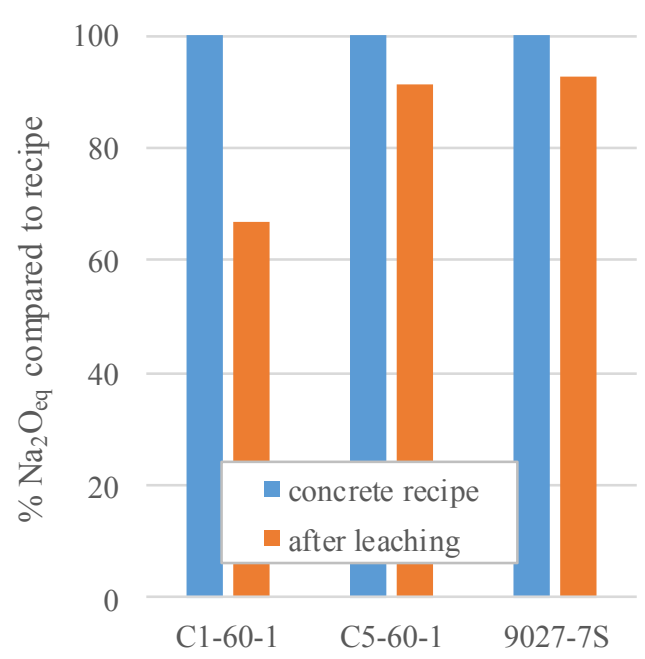

Fig. 16 : The $\% \mathrm{Na}_{2} \mathrm{O}_{\text {eq }}$ left in the concrete after leaching compared to the alkali content initially in the concrete (concrete recipe, Table 2).

Fig. 17 shows the share of the free alkali left in the inner sections of the concretes measured by CWE compared to the initial (design) alkali content (Table 2); in other words, the portion of alkalis that is soluble after the exposure using a cold water extraction method on powdered concrete relative to the design alkali content (considering that there is little leaching in the inner part of the specimens). The percentage is about $50-60 \%$ for all investigated samples. If we assume that the inner sections investigated with CWE have not leached considerably (based on the discussion above), we could compare these values with values obtained in a previous study using sealed samples [6]. The values obtained in the current study agree rather well with the findings by Plusquellec et al., who reported approx. $60 \%$ of free alkali for Portland cement mortar and $40 \%$ of free alkali for fly ash Portland cement (20 wt. $\%$ fly ash). This indicates that the inner sections of the samples haven't leached considerably.

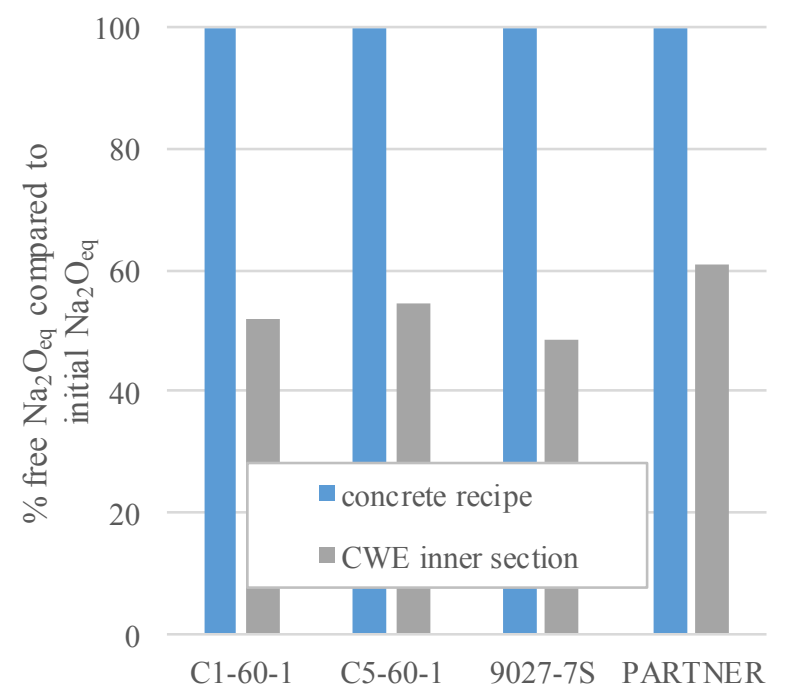

Fig. 17 : The share of the free alkali content left in the inner sections of the initial alkali content of the concrete (Table 2). 
One should note that potential alkali release by the aggregates should be taken into account in such comparisons. However, in all samples except for the 9027-7, limestone aggregates were used. The used limestone is not expected to contribute with alkalis. The 9027-7 sample contains natural sand and cataclasite. Both might contribute with alkalis to the concrete pore water, at least the cataclasite, as it released considerable alkalis when tested according to the draft RILEM AAR-8 alkali release test [9].

\section{Conclusions}

Considerable leaching of alkali metals was documented both in concrete samples exposed to accelerated laboratory testing and in field samples. This has been demonstrated earlier through analysis of the leachate over time. The results presented in this paper confirm this by CWE and $\mu$ XRF analysis of the solids.

CWE allowed to quantitatively determine the changes in free alkali metal content as a function of the depth. However, CWE cannot account for the changes in the paste content towards a cast surface leading to a seemingly increase in alkali metals.

The $\mu \mathrm{XRF}$ allowed to distinguish paste and aggregates. It allowed thereby to determine qualitative $\mathrm{Na}$ and $\mathrm{K}$ profiles in the cement paste phase of the concrete samples. The laboratory exposed samples showed clear leaching profiles in to a depth of about $15 \mathrm{~mm}$ after 21 weeks of exposure at $60{ }^{\circ} \mathrm{C}$. Corresponding numbers for the 12 years field exposed cube were $50-60 \mathrm{~mm}$.

Based on the alkali profiles obtained by $\mu \mathrm{XRF}$, the amount of alkalis leached from the middle section of the prisms was estimated. As the alkali metal content in the paste of the laboratory exposed samples did not increase towards the exposed surface and the paste content clearly did, one could attribute the increase in alkali metal content observed by CWE to an increase in the paste content. Potential Wick action in the field sample could not be ruled due to missing elemental map at the exposed surface.

Alkali sorption by alkali-silica gel was detected using the $\mu \mathrm{XRF}$. Further research is needed to be able to use the $\mu \mathrm{XRF}$ results more quantitatively.

For the laboratory exposed samples, the amount of leached alkalis was also determined by analysing the leachate. The prisms prepared with Portland fly ash cement leached less compared to the prisms prepared with ordinary Portland cement, as expected. The leaching from the prisms estimated based on the $\mu \mathrm{XRF}$ profiles agreed rather well with the level of alkali leaching determined based on the analysis of the leachate.

The free alkali content determined by CWE in the inner sections of the prisms was about $50-60 \%$ of the initial (design) alkali content in the prisms, which indicates that these sections hadn't leached considerably.

\section{References}

1. M.D.A. Thomas, M., B. Fournier, K. Folliard, J. Ideker, M. Shehata, Cement and Concrete Research, 36 (10), p. 1842-1856 (2006).

2. J. Lindgård, M.D.A. Thomas, E.J. Sellevold, B. Pedersen, Ö. Andiç-Çakır, H. Justnes, T.F. Rønning, Cement and Concrete Research, 53, p. 68-90 (2013).

3. J. Lindgård, P.J. Nixon, I. Borchers, B. Schouenborg, B.J. Wigum, M. Haugen, U. Åkesson, Cement and Concrete Research, 40 (4), p. 611-635 (2010).

4. NorwegianConcreteAssociation, NB32, p. 39 (2005).

5. RILEM Recommendations for the Prevention of Damage by Alkali-Aggregate Reactions in New Concrete Structure, 17, Springer, pp. 168 (2016).

6. G. Plusquellec, M.R Geiker, J. Lindgård, J. Duchesne, B. Fournier, K. De Weerdt, Cement and Concrete Research, 96, p. 13-26 (2017).

7. Lindgård, J. (editor), COIN project report 27, ISBN: 978-82-536-1209-6, p. 164 (2011).

8. J. Lindgård, Ö. Andiç-Çakır, I. Fernandes, T.F. Rønning, M.D.A. Thomas, Cement and Concrete Research, 42 (2), p. 223-243 (2012).

9. J. Lindgård, NTNU - Norwegian University of Science and Technology, PhD thesis 269, p. 237 (2013). 